\title{
THE CRYSTAL STRUCTURE OF TRICYCLOHEXYLTIN N-n-BUTYL DITHIOCARBAMATE
}

\author{
Xueqing Song* ${ }^{1}$, Christopher Cahill ${ }^{2,3}$, and George Eng ${ }^{1}$
}

${ }^{1}$ Department of Chemistry and Physics, University of the District of Columbia, Washington, DC 20008

-Department of Chemistry, George Washington University, Washington, DC 20052

${ }^{3}$ Geophysical Laboratory, Carnegie Institute of Washington, Washington, DC 20015

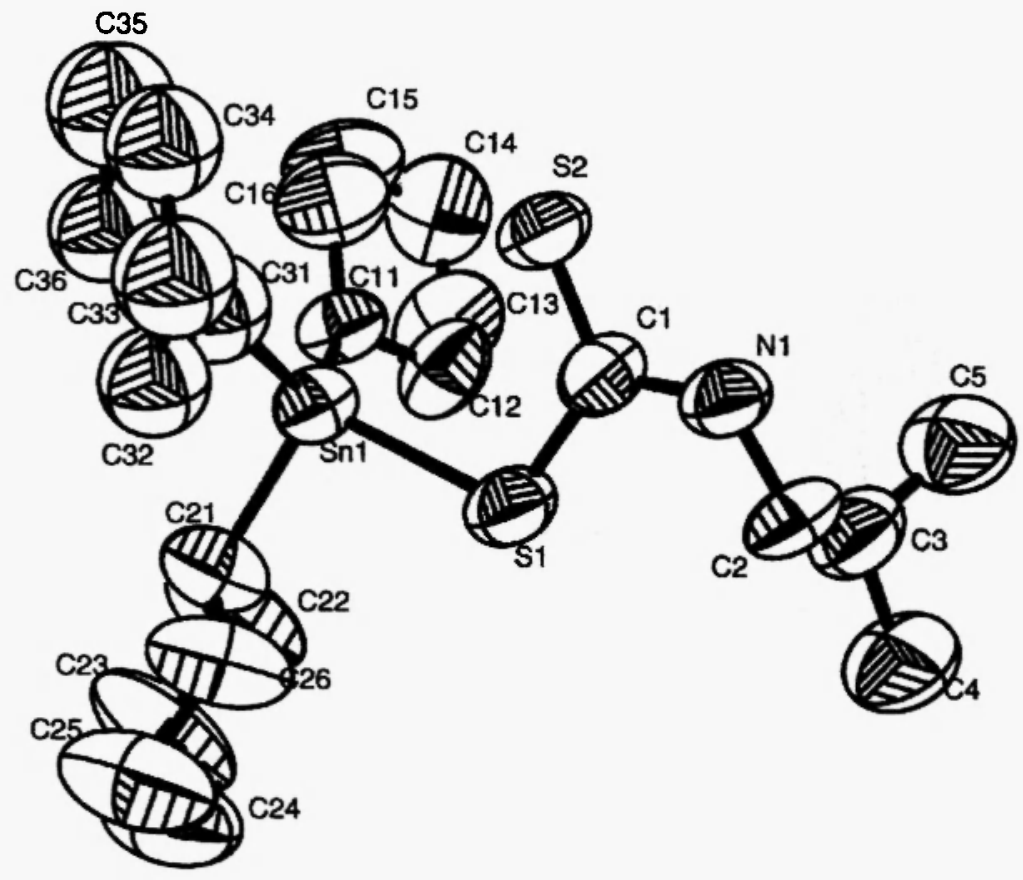

Figure 1. Molecular structure of $\left[\mathrm{Cy}_{3} \mathrm{SnS}_{2} \mathrm{CNHBu}^{n}\right]$. Selected bond distances and angles: $\mathrm{Sn}(1)-\mathrm{C}(11)$ 2.147(8), Sn(1)-C(21) 2.157(9), Sn(1)-C(31) 2.105(11), Sn(1)-S(1) 2.472(3), C(1)-S(1) 1.750(9), C(1)-S(2) $1.656(9), C(1)-\mathrm{N}(1) 1.342(9) ; \mathrm{C}(11)-\mathrm{Sn}(1)-\mathrm{C}(21)$ 107.5(4), C(11)-Sn(1)-C(31) 120.0(4), C(21)-Sn(1)$\mathrm{C}(31)$ 104.9(4), S(1)-Sn(1)-C(11) 110.2(3), S(1)-Sn(1)-C(21) 96.1(3), S(1)-Sn(1)-C(31) 114.8(3), S(1)$\mathrm{C}(1)-\mathrm{S}(2)$ 122.7(5), C(1)-S(1)-Sn(1) 99.8(3), N(1)-C(1)-S(1) 114.9(7), N(1)-C(1)-S(2) 122.4(7). H-atoms omitted for clarity.

\section{Comment}

Dithiocarbamate (dtc) complexes have been examined extensively in organotin complexes of the type $\mathrm{R}_{n} \mathrm{Sn}(\mathrm{dtc})_{4-n}(\mathrm{n}=1-4)$ using various methods such as ${ }^{119} \mathrm{Sn} N \mathrm{NM}$, Infrared and Mőssbauer spectroscopies as well as crystallographic techniques [1]. The bidentate behavior of the dithiocarbamate moiety in $R_{2} \operatorname{Sn}(\mathrm{IV})$ and RSn(IV) N, N'-disubstituted dithiocarbamates is well established [1]. The coordination of dithiocarbamate ligands has been reported in the literature as either of bidentate or anisobidentate. Anisobidentate coordination involves the second sulfur atom being partially weakly bonded to the tin atom. Bidentate bonding is exhibited in the crystal structure of $\mathrm{Ph}_{2} \mathrm{Sn}\left(\mathrm{S}_{2} \mathrm{CNEt}_{2}\right)_{2}$, whereas $\mathrm{Ph}_{3} \mathrm{SnS}_{2} \mathrm{CNEt}_{2}$, $\mathrm{Ph}_{3} \mathrm{SnS}_{2} \mathrm{CN}\left(\mathrm{CH}_{2}\right)_{4}$ and other organotin dithiocarbamates display anisobidentate coordination [1-4]. In the crystal structure of tricyclohexyltin $\mathrm{N}$-n-butyl dithiocarbamate, $\mathrm{Cy}_{3} \mathrm{SnS}_{2} \mathrm{CNHBu}^{\mathrm{n}}$, the overall chelating mode of the dithiocarbamate is anisobidentate, as evidenced by the presence of two different Sn-S distances: $\mathrm{Sn}(1)-\mathrm{S}(1), 2.472(3)$ and $\mathrm{Sn}(1)-\mathrm{S}(2), 3.239(3) \AA$. 
Experimental

Preparation: The title compound was prepared by the slow addition, with stirring, of the sodium salt of N, $\mathrm{N}^{\prime}$-n-butyl dithiocarbamate $(0.35 \mathrm{~g}, 2 \mathrm{mmol})$ to a solution of tricyclohexylyltin chloride $(0.77 \mathrm{~g}, 2 \mathrm{mmol})$ in $50 \mathrm{~mL}$ of acetone. The temperature was kept below $-20^{\circ} \mathrm{C}$ using an acetone/liquid nitrogen bath. The resulting solution was then allowed to evaporate at $-10^{\circ} \mathrm{C}$ under vacuum and a white powder was obtained. Colorless prism crystals were then obtained by the slow evaporation of a dilute solution in ether. The melting point for the crystals was $99-101{ }^{\circ} \mathrm{C}$. Elemental analysis (Schwarzkopf Microanalytical Laboratory, USA) calculated (found) for $\mathrm{C}_{23} \mathrm{H}_{43} \mathrm{NS}_{2} \mathrm{Sn}$ : C 53.96 (53.49), H 8.69 (8.39), Sn 22.98 (22.98) \%. Crystallography: Some positional disorder is present in one cyclohexane ring (C31-C36). In light of this, these carbon atoms were refined isotropically.

Table 1. Crystal data for $\left[\mathrm{Cy}_{3} \mathrm{SnS}_{2} \mathrm{CNHBu}^{\mathrm{n}}\right]$

\begin{tabular}{|c|c|c|c|}
\hline Formula & $\mathrm{C}_{23} \mathrm{H}_{43} \mathrm{NS}_{2} \mathrm{Sn}$ & Formula weight & 516.39 \\
\hline Crystal system & Monoclinic & Crystal size, $\mathrm{mm}$ & $0.046 \times 0.070 \times 0.232$ \\
\hline Space Group & $\mathrm{P} 2_{1} / \mathrm{c}$ & a, $\AA$ & $12.245(5)$ \\
\hline $\mathrm{B}, \AA$ & $17.968(5)$ & c, $\AA$ & $11.916(5)$ \\
\hline$\beta,{ }^{\circ}$ & $93.796(5)$ & $\mathrm{V}, \AA^{3}$ & $2616.0(17)$ \\
\hline Z & 4 & Diffractometer & Bruker, SMART CCD \\
\hline Temperature, $\mathrm{K}$ & $293(2)$ & $\mu(\mathrm{Mo}-\mathrm{K} \alpha), \mathrm{cm}^{-1}$ & 11.45 \\
\hline $\mathrm{D}_{\text {calcd, }}, \mathrm{g} \mathrm{cm}^{-3}$ & 1.311 & $\mathrm{~F}(000)$ & 1080 \\
\hline$\theta_{\max }$ & 25.60 & Reflns unique & 4190 \\
\hline Reflns with $I \geq 2 \sigma(I)$ & 1855 & No. parameters & 232 \\
\hline Weighting Scheme & $\begin{array}{l}1 /\left[\sigma^{2}\left(\mathrm{Fo}^{2}\right)+(0.0440 \mathrm{P})^{2}\right] \\
\mathrm{P}=\left(\mathrm{Fo}^{2}+2 \mathrm{Fc}^{2}\right) / 3\end{array}$ & $R(F), R_{w}(F)$ & $0.053,0.113$ \\
\hline$\rho, \mathrm{e}^{-3}$ & 0.55 & Goodness-of-fit & 0.98 \\
\hline Programs used & \multirow{2}{*}{\multicolumn{3}{|c|}{ SIR97 [5], SHELXTL [6], WINGX [7], ORTEP [8] }} \\
\hline Deposition number & & & \\
\hline
\end{tabular}

Acknowledgements

Financial support from the National Institutes of Health Minority Biomedical Research Support Program (MBRS/SCORE, GM08005) is gratefully acknowledged.

References

[1] E. M. Holt, F. A. K. Nasser, A. Wilson, Jr. and J. J. Zuckermann, Organometallics, 4 (1985) 2073.

[2] S. Chandra, B. D. James, R. J. Magee, W. C. Patalinghug, B. W. Skelton and A. H. White, J. Organomet. Chem., 346 (1988) 7.

[3] E. R. T. Tiekink, Main Group Met. Chem., 15 (1992) 161.

[4] E. R. T. Tiekink, Main Group Met. Chem., 16 (1993) 129.

[5] A. Altomare, M. C. Burla, M. Camalli, G. L. Cascarano, C. Giacovazzo, A. Guagliardi, A. G. G Moliterni, G. Polidori and R. Spagna, J. Appl. Cryst. 32 (1999) 115.

[6] SHELXTL NT, V5.IProgram suite for solution and refinement of crystal structures, Bruker Analy tical X-ray Systems, Madison, WI., 1998.

[7] L. J. Farrugia, J. Appl. Cryst., 32 (1999) 837.

[8] C. K. Johnson, ORTEP, Report ORNL-5138 (1976), Oak Ridge National Laboratory, TN, USA 